\title{
Physical Distancing, Violence, and Crime in US Cities during the Coronavirus Pandemic
}

\author{
Julia P. Schleimer (D) Christopher D. McCort - Elizabeth A. Tomsich • \\ Veronica A. Pear • Alaina De Biasi • Shani Buggs · Hannah S. Laqueur • \\ Aaron B. Shev $\cdot$ Garen J. Wintemute
}

Accepted: 10 November 2021/Published online: 29 November 2021

(C) The New York Academy of Medicine 2021

\begin{abstract}
Violent crime increased and most property crime decreased in many United States (US) cities during the coronavirus pandemic. Using negative binomial regressions, we examined the association between physical distancing (a central coronavirus containment strategy) and crime within 16 large cities (in 12 US states and the District of Columbia) through July 2020. Physical distancing was measured with aggregated smartphone data and defined as the average change in the percentage of the population staying completely at home. Outcome data were obtained from the Gun Violence Archive and city open data portals. In multivariable models, increases in the percentage of the population staying home were associated with decreases in reported incidents
\end{abstract}

Supplementary Information The online version contains supplementary material available at https://doi. org/10.1007/s11524-021-00593-4.

J. P. Schleimer $(\bowtie) \cdot$ C. D. McCort · E. A. Tomsich •

V. A. Pear - A. De Biasi - S. Buggs · H. S. Laqueur ·

A. B. Shev · G. J. Wintemute

Department of Emergency Medicine, School of Medicine,

Violence Prevention Research Program, University

of California, Davis, 2315 Stockton Blvd, Sacramento, CA 95817, USA

e-mail: jpschleimer@ucdavis.edu

J. P. Schleimer · C. D. McCort · E. A. Tomsich ·

V. A. Pear - A. De Biasi - S. Buggs · H. S. Laqueur ·

A. B. Shev · G. J. Wintemute

California Firearm Violence Research Center, Sacramento,

CA, USA of aggravated assault, interpersonal firearm violence, theft, rape, and robbery, and increases in arson, burglary, and motor vehicle theft. Results suggest that changes in the frequency of interpersonal interactions affected crime during the coronavirus pandemic. More research is needed on the specificity of these assocations and their underlying mechanisms.

\section{Introduction}

In 2019, 19,141 people died from homicide in the United States (USA) and many more sustained nonfatal violent injuries or were victims of violent crime $[1,2]$. Exposure to violence-including direct victimization, witnessing and hearing about violence, and living in an area where violence is common-carries substantial health and social costs (e.g., premature mortality, depression, and reduced economic productivity) [3]. Exposure to property crime (e.g., burglary, theft) may also result in diminished health and wellbeing by affecting perceptions of safety and, in turn, negatively impacting mental distress, outdoor physical activity, and social capital [4].

Violent crime increased and most property crime decreased in many US cities during the coronavirus pandemic [5]. Identifying the factors associated with these changes may advance our understanding of the etiologies of crime and inform opportunities for prevention. 
One such factor may have been adherence to shelter-in-place recommendations (i.e., physical distancing). Physical distancing was a coronavirus containment strategy, though uptake of shelter-in-place guidelines varied across places [6]. Areas with greater adherence may have experienced reduced rates of crime due to a lack of opportunity if fewer offenders and potential targets were in public, or they may have experienced increased rates if fewer capable guardians were present to intervene [7]. For the same reasons, physical distancing may have reduced residential property crime (via added guardianship of home and property), but increased violence at home (as persons in violent relationships spent more time together under conditions of stress and isolation). Physical distancing also disrupted social ties by separating people from friends, school, and work and interrupted access to support services. These changes may specifically increase violence, for example, by increasing aggression, weakening social capital, or hampering community violence interventions.

Several research studies have examined the link between shelter-in-place policies or their adherence and crime during the pandemic [8-15]. Some have noted an associated reduction in robbery and theft, but results have been mixed for violent crimes other than robbery. There are some limitations to the available evidence. Binary policy indicators (i.e., whether a shelter-in-place order was in effect or not) [8, 12-15] do not account for compliance, for example. Studies that compare change over time in a single place [11, $12,14,15]$ (or across places with no variation in the timing of policy implementation) [13] may be more vulnerable to confounding than studies that leverage greater variation in exposure over time and place. Moreover, few studies have examined the association between shelter-in-place policies and firearm violence $[8,13-15]$, a particularly severe form of violence that imposes substantial societal costs [3].

In the current study, we add to the evidence on the relationships between adherence to shelter-in-place recommendations during the coronavirus pandemic and violent and property crime rates. We focus on 16 major cities in the USA and the acute phase of the pandemic during the summer of 2020, addressing the aforementioned gaps in the literature. Research on the associations between physical distancing and crime during this pandemic may inform responses to a range of events, including the next pandemic, extreme weather, and other crises or natural disasters that affect mobility and routine activities of daily life [16].

\section{Methods}

\section{Study Population}

In this repeated cross-sectional study from January 2018-July 2020, we estimated associations between changes in the percentage of the city population sheltering in place and crime and violence incidents within 16 major US cities (in 12 states and the District of Columbia): Baltimore, MD; Boston, MA; Chicago, IL; Cincinnati, OH; Dallas, TX; Denver, CO; Detroit, MI; District of Columbia; Los Angeles, CA; Milwaukee, WI; Philadelphia, PA; Phoenix, AZ; Riverside, CA; Sacramento, CA; San Francisco, CA; and Seattle, WA. The unit of analysis was city-days.

\section{Exposure}

Using anonymized, aggregated smartphone data from SafeGraph [17], we measured physical distancing as the average change in the percentage of the city population staying completely at home compared to baseline (the week ending February 12, 2020, per SafeGraph's "Shelter in Place" index). A smartphone device was considered completely at home in a given day if it did not leave the location $(\sim 153 \mathrm{~m} \mathrm{x} \sim 153 \mathrm{~m}$ cell) in which it spent the majority of nights in the prior 6-week period [17]. By using smartphone data, we capture the continuum of adherence to shelter-inplace guidelines and maximally leverage variation within and between cities over time.

\section{Outcomes}

We included 9 outcomes, all measured as the number of incidents per city-day (data on the number of victims were not consistently available): instances of intentional, interpersonal firearm violence, defined as shootings in which at least one person was injured or killed, obtained from the Gun Violence Archive [18]; and the 8 Federal Bureau of Investigation Uniform Crime Reporting (UCR) Part I crimes, which include 4 violent crimes (homicide, rape, robbery, aggravated assault) and 4 property crimes (burglary, larcenytheft, motor vehicle theft, arson). 
The Gun Violence Archive [18] compiles reports from approximately 7500 sources, including the news media, police, and government. The 8 UCR outcomes were measured with publicly-available policereported crime incident data, obtained from city data portals. See Supplementary Table 1 for information about data sources.

\section{Analysis}

We separately modeled each outcome with negative binomial regressions. Models included indicators for cities and the exposure period (beginning February 13, 2020), an overall linear time trend, sin-cosine functions for seasonal and weekly cycles [19], and city-specific time-varying covariates: cumulative coronavirus cases and deaths per population, shelterin-place orders, incidents of police violence at events protesting the murder of George Floyd during the summer of 2020 per population, attendees at protests related to racial justice and policing per population, temperature, and precipitation. Models included the $\log$ of the city population as an offset and a covariate to allow for an association between population change within cities and crime [20]. See Supplementary Table 2 for additional information about the covariates and their data sources. Physical distancing and police violence were specified as 7-day moving averages to reduce noise and remove weekly seasonal variation. We used sandwich covariance matrix estimators for hypothesis tests and confidence intervals (CIs), alpha of 0.05 (2-sided), and controlled the false discovery rate to adjust for multiple testing. Analyses were done in $\mathrm{R}$ version 4.0.0 ( $\mathrm{R}$ Project for Statistical Computing). The University of California, Davis Institutional Review Board approved this study.

\section{Results}

Across cities, the percentage of the population staying completely at home was highest in April and early May, though it remained above the pre-pandemic baseline through July (Supplementary Fig. 1). There was considerable variation in the magnitude of physical distancing between cities over time (median 9.3; interquartile range 3.7-14.6).
Larceny-theft was the most common crime, and homicide was least common (Supplementary Table 3). Pandemic-era changes varied across outcomes, with increases in several violent crimes.

In multivariable models, a 5\% increase in the percentage of the population staying home per day was associated with a decrease in aggravated assault (rate ratio [RR]: 0.98; 95\% CI: 0.96-0.99), interpersonal firearm violence (RR: 0.94; 95\% CI: 0.90-0.99), larceny-theft (RR: 0.91 ; 95\% CI: 0.90-0.91), rape (RR: 0.91; 95\% CI: 0.86-0.96), and robbery (RR: 0.96; 95\% CI: 0.94-0.97), and an increase in arson (RR: 1.07; 95\% CI: 1.02-1.12), burglary (RR: 1.07 ; $95 \%$ CI: 1.05-1.08), and motor vehicle theft (RR: 1.09; 95\% CI: 1.08-1.11) (Table 1). The association with homicide was not statistically distinguishable from the null.

\section{Discussion}

Among 16 major US cities, increased physical distancing during the coronavirus pandemic - a measure of adherence to shelter-in-place recommendationswas associated with decreases in reported incidents of aggravated assault, interpersonal firearm violence, theft, rape, and robbery, and increases in arson, burglary, and motor vehicle theft from February 2020 through July 2020. We did not find an association between physical distancing and homicide. Our results are similar to those from some prior studies, which found no association between shelter-in-place policies or adherence and homicide; $[8,10]$ a decrease in aggravated assault [8], theft [8, 10, 13], robbery $[8,10,13]$, rape, [8] and gun-related crime; [13] and an increase in (non-residential) burglary [8]. Unlike our study, other previous studies found an increase in shootings $[14,15]$ or no association or mixed findings for burglary [9-11], robbery [11], motor vehicle theft [8, 10, 11], assault [9-11], and shootings [8].

Findings from the current study are consistent with the routine activities theory of crime, suggesting that, as more people sheltered-in-place during the pandemic, accompanying shifts in routine activities of daily life decreased or increased the opportunity for certain crimes to occur [7]. There was a negative association with most outcomes that involve direct confrontation-usually in public-between a victim 


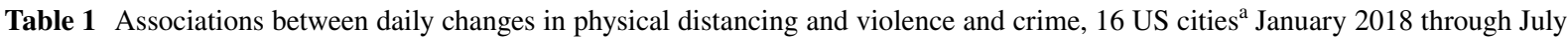
2020

\begin{tabular}{|c|c|c|c|c|c|c|}
\hline \multirow[t]{2}{*}{ Outcome } & \multicolumn{3}{|c|}{ Unadjusted $^{\mathrm{b}}$} & \multicolumn{3}{|c|}{ Adjusted $^{c}$} \\
\hline & $\mathrm{RR}^{\mathrm{d}}$ & $95 \%$ & & $\mathrm{RR}^{\mathrm{d}}$ & $95 \%$ & \\
\hline Aggravated Assault & 1.00 & 0.99 & 1.00 & $0.98^{\mathrm{e}}$ & 0.96 & 0.99 \\
\hline $\operatorname{Arson}^{\mathrm{f}}$ & $1.09^{\mathrm{e}}$ & 1.06 & 1.12 & $1.07^{\mathrm{e}}$ & 1.02 & 1.12 \\
\hline Burglary & $1.05^{\mathrm{e}}$ & 1.04 & 1.05 & $1.07^{\mathrm{e}}$ & 1.05 & 1.08 \\
\hline Homicide & $1.05^{\mathrm{e}}$ & 1.02 & 1.08 & 0.99 & 0.92 & 1.05 \\
\hline Interpersonal firearm violence & $1.04^{\mathrm{e}}$ & 1.01 & 1.06 & $0.94^{\mathrm{e}}$ & 0.90 & 0.99 \\
\hline Larceny-theft & $0.90^{\mathrm{e}}$ & 0.89 & 0.90 & $0.91^{\mathrm{e}}$ & 0.90 & 0.91 \\
\hline Motor vehicle theft & $1.05^{\mathrm{e}}$ & 1.04 & 1.06 & $1.09^{\mathrm{e}}$ & 1.08 & 1.11 \\
\hline Rape $^{g}$ & $0.88^{\mathrm{e}}$ & 0.86 & 0.90 & $0.91^{\mathrm{e}}$ & 0.86 & 0.96 \\
\hline Robbery & $0.92^{\mathrm{e}}$ & 0.91 & 0.92 & $0.96^{\mathrm{e}}$ & 0.94 & 0.97 \\
\hline
\end{tabular}

${ }^{a}$ Cities include: Baltimore, MD; Boston, MA; Chicago, IL; Cincinnati, OH; Dallas, TX; Denver, CO; Detroit, MI; District of Columbia; Los Angeles, CA; Milwaukee, WI; Philadelphia, PA; Phoenix, AZ; Riverside, CA; Sacramento, CA; San Francisco, CA; and Seattle, WA

${ }^{b}$ Unadjusted results are from separate negative binomial regression models with the log of the population as an offset, indicators for cities, a linear time trend, and sin-cosine functions for seasonal and weekly cycles

${ }^{c}$ Adjusted results are from separate negative binomial regression models with the log of the population as an offset and covariate; indicators for cities and the exposure period (beginning February 13, 2020); a linear time trend; sin-cosine functions for seasonal and weekly cycles; and time-varying covariates: coronavirus cases and deaths per population; stay-at-home orders; incidents of police violence at events protesting the murder of George Floyd during the summer of 2020 per population; attendees at protests related to racial justice and policing per population; temperature; and precipitation

${ }^{\mathrm{d}}$ Rate ratios (RR) reflect the change in the outcome associated with a 5-percentage point increase in physical distancing

${ }^{\mathrm{e}} \mathrm{P}<0.05$

${ }^{\mathrm{f}}$ Riverside, CA and Cincinnati, $\mathrm{OH}$ are excluded due to missing outcome data

${ }^{g}$ Boston, MA; Dallas, TX; Detroit, MI; District of Columbia; Milwaukee, WI; Riverside, CA; and Sacramento, CA are excluded due to missing outcome data

All outcomes reflect incidents (rather than victims)

and offender (e.g., robbery). In contrast, physical distancing was positively associated with outcomes that often occur in public, without interpersonal interaction, and when no one is around to intervene (e.g., motor vehicle theft). The relationships with aggravated assault and rape may be the result of fewer social interactions, or they could be artifacts of reporting if coronavirus-related physical distancing limited victims' ability or willingness to report abuses. This source of measurement error is less likely for interpersonal firearm violence and homicide.

Overall, homicide, shootings (both lethal and nonlethal), and aggravated assault all increased during the pandemic. Our results suggest that, for firearm violence and assault, these increases were larger in cities with less physical distancing.

The data used in the current study do not allow us to differentiate for all cities whether incidents occurred indoors or outdoors (or, if indoors, in residences or other locales). It is possible that adherence to shelter-in-place policies was differentially associated with violence at home versus in public, and these differences would be averaged in our measures of violence. There is some evidence that shelter-in-place policies may have been associated with increases in domestic violence specifically $[11,13]$, though findings have been mixed $[8,10,12]$. We were only able to identify domestic violence incidents in a minority of city data portals; future research will examine the association of physical distancing and domestic violence in relation to characteristics of neighborhoods within these cities.

Other limitations include reliance on policereported crimes, possible measurement error, nonrepresentativeness, and unmeasured confounding (e.g., cities that adhered to physical distancing 
guidance more strongly may have systematically differed from other cities). Results may not generalize to other cities, non-urban areas, or to contexts outside of the pandemic. Our selection of 16 large US cities was based on convenience in accessing data.

Overall, results suggest that changes in the frequency of interpersonal interactions affected crime during the coronavirus pandemic. Future research should assess whether the observed associations with aggravated assault and rape are real or an artifact of decreased reporting during the pandemic. Additional analyses-including at finer geographic units and with more detailed data on the nature and location of incidents - would add to the evidence on whether and how physical distancing was related to various types of crime during the pandemic.

Acknowledgements This work was supported by the Joyce Foundation (grant no. 42400), the Heising-Simons Foundation (grant no. 2019-1728), and the California Firearm Violence Research Center.

\section{References}

1. Centers for Disease Control and Prevention. Fatal Injury Data. Web-based Injury Statistics Query and Reporting System (WISQARS). https://www.cdc.gov/injury/wisqa rs/fatal.html. Accessed 1 Aug 2021

2. Bureau of Justice Statistics (BJS) - Criminal Victimization, 2019. https://www.bjs.gov/index.cfm?ty=pbdetail\& iid=7046. Accessed 28 Jan 2021

3. Rivara F, Adhia A, Lyons V, et al. The effects of violence on health. Health Aff (Millwood). 2019;38(10):1622-9. https://doi.org/10.1377/hlthaff.2019.00480.

4. Dustmann C, Fasani F. The effect of local area crime on mental health. Econ J. 2016;126(593):978-1017. https:// doi.org/10.1111/ecoj.12205.

5. Rosenfeld R, Abt T, Lopez E. Pandemic, Social Unrest, and Crime in U.S. Cities, 2020 Year-End Update. 2021. https://online.ucpress.edu/fsr/article/33/1-2/72/115493/ Pande mic-Social-Unrest-and-Crime-in-U-S-Cities. Accessed 4 Feb 2021.

6. Ingram M, Zahabian A, Hur C. Prediction of COVID-19 social distancing adherence (SoDA) on the United States county-level. Humanit Soc Sci Commun. 2021;8(1):1-7. https://doi.org/10.1057/s41599-021-00767-0.

7. Cohen LE, Felson M. Social change and crime rate trends: a routine activity approach. Am Sociol Rev. 1979;44(4):588-608. https://doi.org/10.2307/2094589.
8. Abrams DS. COVID and crime: an early empirical look. $J$ Public Econ. 2021;194:104344. https://doi.org/10.1016/j. jpubeco.2020.104344.

9. Campedelli GM, Favarin S, Aziani A, Piquero AR. Disentangling community-level changes in crime trends during the COVID-19 pandemic in Chicago. Crime Sci. 2020;9(1):21. https://doi.org/10.1186/ s40163-020-00131-8.

10. Campedelli GM, Aziani A, Favarin S. Exploring the immediate effects of COVID-19 containment policies on crime: an empirical analysis of the short-term aftermath in Los Angeles. Am J Crim Justice. 2021;46(5):704-727. https://doi.org/10.1007/s12103-020-09578-6.

11. Mohler G, Bertozzi AL, Carter J, et al. Impact of social distancing during COVID-19 pandemic on crime in Los Angeles and Indianapolis. J Crime Justice. 2020;68:101692. https://doi.org/10.1016/j.jcrimjus.2020. 101692.

12. Piquero AR, Riddell JR, Bishopp SA, Narvey C, Reid JA, Piquero NL. Staying home, staying safe? A short-term analysis of COVID-19 on Dallas domestic violence. Am J Crim Justice. 2020;45(4):601-35. https://doi.org/10.1007/ s12103-020-09531-7.

13. Bullinger LR, Carr JB, Packham A. COVID-19 and crime. Am J Health Econ. 2021;7(3):249-280. https://doi.org/10. 1086/713787.

14. Kim D-Y, Phillips SW. When COVID-19 and guns meet: a rise in shootings. J Crime Justice. 2021;73:101783. https://doi.org/10.1016/j.jcrimjus.2021.101783.

15. Beard JH, Jacoby SF, Maher Z, et al. Changes in shooting incidence in Philadelphia, Pennsylvania, between march and November 2020. JAMA. 2021;325(13):1327-1328. https://doi.org/10.1001/jama.2021.1534.

16. Mares D. Climate change and levels of violence in socially disadvantaged neighborhood groups. J Urban Health Bull N Y Acad Med. 2013;90(4):768-83. https://doi.org/10. 1007/s11524-013-9791-1.

17. Social Distancing Metrics. SafeGraph. https://docs.safeg raph.com/docs/social-distancing-metrics. Accessed 1 Oct 2020.

18. Gun Violence Archive. General Methodology. https:// www.gunviolencearchive.org/methodology. Accessed 23 Jan 2021.

19. Ramanathan K, Thenmozhi M, George S, et al. Assessing seasonality variation with harmonic regression: accommodations for sharp peaks. Int $J$ Environ Res Public Health. 2020;17(4):1318. https://doi.org/10.3390/ijerp h17041318.

20. Cornell Statistical Consulting Unit. To Offset or Not: Using Offsets in Count Models Statnews \#94.; 2020.

Publisher's Note Springer Nature remains neutral with regard to jurisdictional claims in published maps and institutional affiliations. 